\title{
Domínio e "gerenciamento" da propriedade familiar no mundo antigo: as contribuições de Catão Censor e Xenofonte
}

\author{
Matheus Trevizam
}

Resumo: Dans cet article, nous proposons une lecture comparative de l'Économique de Xenophon et du De agri cultura catonien au point de vue de l'organisation interne des domaines familiaux et des buts de leur gestion. Par cela, on attend exposer quelque chose de ce terrain "restraint" de la vie ancienne, arriver aux caractéristiques intrinsèques d'un ouvrage par rapport à l'autre et, dans une mesure réduite, des deux par rapport au monde extérieur.

Palavras-Chave: vie "domestique" dans l'Antiquité; gestion des biens familiaux; organisation des parties privées de la vie de l'homme ancien; rapports de société; Xenophon d'Athènes; Caton l'Ancien.

\section{Introdução}

Catão Censor e o escritor socrático Xenofonte têm em comum, além da poligrafia ${ }^{1}$ e de trajetórias pessoais, às suas respectivas maneiras, muito movimentadas, ${ }^{2}$ o interesse pelo tema da organização dos fazeres (inclusive pro-

Mateus Trevizam é professor da UFMG.

Organon, Porto Alegre, $n^{0}$ 44/45, janeiro-dezembro, 2008, p. 103-116 
dutivos) no âmbito da vida privada dos cidadãos. Referimo-nos, com isso, às iniciativas de composição de obras instrucionais associáveis, no primeiro caso, econômico, nas quais se tem a possibilidade ao De agricultura senhores de ultrapassar os limites a franquearem os dominios

para divisar por instantes algo de seu funcionamento.

Nesse sentido, as obras mencionadas possibilitam-nos estabelecer um contraponto para a valorizada imagem dos indivíduos livres (e minima antiga enfavorecidos por seu nascimento) nas sociedades ateniense eromar quanto plenos participantes da vida cívica, ao mesmo tempo em que, por uma feliz exceção, põem em cena sob foco central certos segmentos sociais relegados a sezundo pois, se não estivéssemos cientes dos artes 位 cativas para equivocar-nos a respeito da importância de outros participantes no todo da vida social antiga. É que parte dos principais gêneros compositivos da Antigüidade (epopéia, oratória epidítica, forense e deliberativa, história, di(ecola comportamentos vinculados ao álogo, por vezes a tragédia) favorece acolher comportamentos vinculados ao universo dos homens em relações variadas com seus pares numa dimensão interacional mais vasta.

Esse, por exemplo, é o caso das epopéias e tragédias que têm como protagonistas humanos imponentes figuras de reis e heróis (caso típico de Aquiles, nistá Enéias e Édipo), dos discursos públicos de Demóstenes ou de Cícero, respectivamente destinados à audição nas assembléias atenienses e no senado romano, dos relatos dos historiadores antigos (Heródoto, ${ }^{4}$ Salústio, etc. ${ }^{5}$ ), tão voltados, como sabemos, para propósitos de eternização de "grandes feitos" de "grandes en velón compreendido como homens" e, por fim, do gênero dialogico, diversas vezes compros num círculo meio de discussão de questões de interesse filosófico ${ }^{6}$ conduzidas num circulo interacional exclusivamente masculino.

Ora, se os espaços sociais reivindicados por tais gêneros (a zona da guerra, do bre o mundo) privilegiam a parte ostensiva dos gestos masculinos, o mesmo não se dá compulsoriamente no caso de obras com a natureza do De agri cultura nãose e do Econômico. De fato, como dissemos, seu espaço centrariais, sem, todavia, a sentativo consiste no mundo interno aos domínios senhoriais, semente físico. necessidade premente de os compreendermos unicame

Isso significa, caso atentemos para a distribuição interacional dos membros de tais sociedades nas várias zonas de atuação possíveis, que esse universo interno, mais resguardado dos olhares e influências de terceiros, ao mesmo tempo em que situa o senhor num âmbito cujas características intrínsecas o privam do exclusivismo, ${ }^{8}$ dá margens para uma maior participação daqueles implicados no flexível âmbito "doméstico" (mulheres, criados, jornaleiros, escravos dos campos...).
Com a continuidade da análise comparativa, pois, aproveitaremos a chance

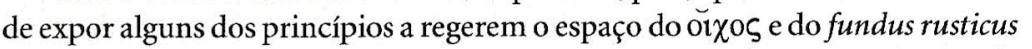
catoniano. Enquanto, entre si, espaços da experiência do homem antigo particularizados pelas culturas em jogo e, ao mesmo tempo, confinantes, acreditamos em que apresentem modos de funcionamento, organização e objetivos mutuamente passíveis de esclarecer-se pelo contraste.

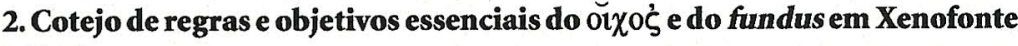
e Catão:

De início, é fundamental esclarecer que os espaços do ỡ os e do fundus rusticus se encontram necessariamente hierarquizados sob a égide do senhor ( ${\text { v́p} 10 \zeta^{9} \text { dominus }}^{10}$ ): a ele cabe, como proprietário, autoridade máxima e condutor principal dos rumos a serem tomados, regrar, em ambos os casos, as atitudes de todos os participantes. Os próprios objetivos da preceituação dada nos textos, por sinal, mantêm vínculos estreitos com a idéia da "instrução" dos senhores a fim de que saibam como desempenhar com competência a essência de seu papel no domínio privado: Catão, bem o revela o conhecimento da obra agrária em questão, concebeu-a com fins de manual prático para os romanos donos de terras direcionadas para a oleicultura ou a viticultura comerciais ${ }^{11}$ no segundo século a.C. Xenofonte, por sua vez, tornando Iscômaco o porta-voz de um certo estrato característico, ${ }^{12}$ fê-lo expor a Sócrates os motivos de sua boa reputação em Atenas, vinculando-a, naquele contexto específico, a um modo de conduta "ideal" que poderia ser imitado pelo interessados.

Curiosamente, no caso do De agri cultura, os minuciosos procedimentos de controle transmitidos ao público, se, por um lado, têm como objetivo último alcançar os ouvidos de um senhor atento, por outro, dadas as condições em que se passam as atividades produtivas no fundus rusticus por ele descrito, acabam, na prática, por serem delegados a outros. Pois, como têm esclarecido os comentadores e vários estudiosos da economia antiga, inserindo-se historicamente numa fase de decisivo alargamento de horizontes para o imperialismo romano, ${ }^{13}$ Catão tematiza, nesse manual, um conjunto de procedimentos de trabalho que não podem mais identificar-se com a estrita atuação de um dominus a cultivar o solo com as próprias mãos. ${ }^{14}$

Com efeito, os tipos de culturas arbóreas mais especializadas e abordadas ali com atenção (oliveiras e videiras) pressupõem não só a vigilância contínua de um responsável como também que se trate de um supervisor especificamente preparado para o bom desempenho de uma minuciosa chefia. Dessa maneira, o senhor romano, doravante desviado para o empenho político em ambiente urbano, ${ }^{15}$ adota como solução para os novos tempos confiar por completo a um subordinado de confiança (o uilicus) a autoridade e a coordenação Organon, Porto Alegre, $\mathrm{n}^{\circ} 44 / 45$, janeiro-dezembro, 2008, p. 103-116 
os esforços do companheiro. ${ }^{28}$ Como se vê, trata-se, conforme anunciamos aci-

das atividades no fundus durante sua ausência.

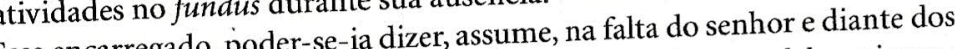
Esse encalternos (a uilica, os escravos e criados rurais de posse dele, os jornadrabalhadores de empreitada a prestarem serviços em caráter sazonal leiros e trabalha àquele, no modelo de exploração ruou temporário), papel muito semelhante aqué, neve, por conseral dos velhos tempos, desempenhado pelo proprio dominus. Deve, guinte, distribuir as tarefas de acordo com as necessidades produtivas (antiga atribuição, imaginamos, do pater familias no trato quotidiano com a prole es poucos escravos a dividirem consigo a faina agrícola), regrar o consumo e a partilha dos bens no âmbito "doméstico,"17 impor a autoridade e a ordem, ${ }^{18}$ providências para controlar o culto (inclusive, abstendo-se de retomar certas providencias pásticas pouco ortodoxas do ponto de vista da religicorrer a algumas práticas misticas pouco ortodoxas do ponto de vista da religiosidade tradicional dos latinos), ${ }^{19}$ contar com a colaboração da uilica para realização da parte dos trabalhos que não the cabe por tratar-se de tarefas apenas concernentes à domus. ${ }^{20}$

O quadro esboçado no Econômico no tocante ao mesmo aspecto do controqua vez, certas particularidades. Assim, Iscômaco, homem prole apresenta, por sum privilégio característicondição de cidadão, ${ }^{22}$ dono atento de terras de plantio, parece, apeco de sua contaboradores, ausentar-se menos dia, sar de contar com líder absoluto do que o correlato romano.

de seu posto de líder absoluto do que o correla

Ele reside pessoalmente na casa urbana apresentada como um dos eixos centrais de estruturação do ơ $\chi 0 \zeta$ tendo-se incumbido, desde o início, do paciente processo educativo da jovem esposa a fim de que se tornasse sua colaborado aumento honrado eficaz num "empreendimento" destinado à manutenção e ao aumento honrado do patrimônio familiar. ${ }^{23}$ É verdade que, desse momento em diante, a mulher passará a ser a "rainha" diligente da "colméia" doméstica, ${ }^{24}$ mas a tutela a em certas passagens, continuará a servir作 the de parametro seguro para não dra urbem, não haverão de furtar-se ao acompaescravos-chefe de suas terras extra urbem, não haverão de furtar-se ao acompahamento próximo (ou mesmo diário) do senhor, já que, entre as atividades rotineiras de Iscômaco, invariavelmente se conta a caminhada a tais domínios. ${ }^{26}$

De volta à questão da atuação da $\mu$ É $\lambda 1 \sigma \sigma \alpha$ na casa de Iscômaco, notamos

que do metade do to

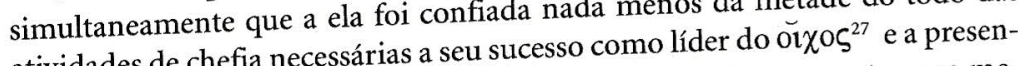
atividades de chefia necessárias a seu sucesso comolider do orxo 27 e a ca do domínio da vida animal aludido a lhor compreender-lhe o modus operandi.

cespécie de divisão de papéis "divinamente

作 estabelecida, Iscomaco explica que, cabendo ao hom mundo externo, compete segurar o ganho dos bens no confronto direto com o mundo exte que não se à esposa guardá-los e organizá-los na segurança do lar a fim de que náo se percam por motivos variados (furto, extravio, avaria), vindo, assim, inutilizar Organon, Porto Alegre, $n^{\circ}$ 44/45, janeiro-dezembro, 2008, p. 103-116 ma, de atribuir à esposa, se não a função de chefia maior, ao menos uma complementaridade ${ }^{29}$ de modo algum negligenciável, tendo em vista o próprio

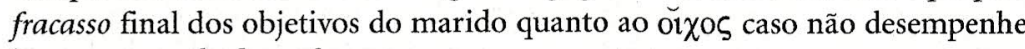
bem sua parcela dos esforcos.

Sobre a proximidade da esposa com a atuação da rainha na colméia de abelhas, uma ilustrativa passagem do Econômico oferece-nos todo um conjunto de pontos comuns entre ambas, ${ }^{30}$ de maneira a esboçar-se um quadro aproximado do essencial dos traços psicológicos da dona da casa. De início, a abelharainha é retratada por Xenofonte como um ser, antes de mais nada, laborioso; ${ }^{31}$ então, cabe-lhe, no comando das operárias, ser ativa e vigiar rigorosa por sua atividade, fazendo com que tanto as que devem trabalhar fora quanto as que devem trabalhar dentro sigam para seus respectivos rumos e não sejam, em hipótese alguma, ociosas ou negligentes; além disso, deve receber os alimentos vindos do exterior, saber como distribuí-los com justiça para o uso dos que necessitam ou guardá-los em segurança.

Atividade, critério, zelo e atenção, pois, são importantes características esperadas da esposa enquanto "braço" do líder no âmbito do lar. Mas ela poderia, no entanto, descentralizando em parte o mando e a responsabilidade que lhe fôra confiada pelo marido, contar com o auxílio de uma "governanta", cujo perfil, por sinal, é assimilável até certo ponto às virtudes de sua senhora. ${ }^{32}$

O trabalho dos intendentes rurais, por outro lado, furta-se por completo à zona de atuação da mulher justamente por vir a ocorrer num espaço não só externo à casa, mas ao próprio $\ddot{\alpha} \sigma \tau v{ }^{33}$ Preferiríamos, portanto, considerar a autoridade desses serviçais enquanto ramificação direta da autoridade do senhor e um correlato preciso daquela da esposa no resguardo do lar. Acaso não se dá que, à parte a completa diferenciação dos ambientes de vigência dos encargos, um e outro sejam sempre os subalternos mais imediatos do kúptó́, visando à efetiva realização de suas vontades?

Desses escravos, de maneira similar ao visto quando comentamos o perfil da esposa (ou, em menor grau, da "governanta"), também se requerem qualidades condizentes com o papel do encarregado (como a lealdade, o alheamento a interesses "inúteis" do tipo do vinho e do amor aos meninos, alguma ambição "sadia"), ${ }^{34}$ prevendo-se ainda que devam ser formados pelo dono para ajustarse perfeitamente à função. Eles, inclusive, de uma maneira que parece espantosa para Sócrates, serão capazes de ensinar os homens sob seu comando a obedecerem, sob efeito de uma "pedagogia régia" em escala reduzida. ${ }^{35}$

A menção às atividades desses participantes da vida no fundus e no ŏ $\chi 0 \zeta$, atuando num e noutro caso "representativamente" e sob comando do senhor, além disso, favorece-nos pensar nos demais pontos "programáticos" das obras de Catão e Xenofonte. Com efeito, pelo que se deve ter ao menos em parte delineado com os comentários a respeito de todos, nunca se trata de indivíduos Organon, Porto Alegre, $\mathrm{n}^{\mathrm{a}}$ 44/45, janeiro-dezembro, 2008, p. 103-116 
comportando-se de maneira aleatória, mas segundo ditames comprometidos com intentos de maior eficácia. Assim, o "mapeamento" estendido de tais nor位 作 agentes (as quais nos passam com clareza diante dos olhos com o exame das obras), auxiliar-nos-á a aprofundar nossa compreensão do significado da experiência "doméstica" em ambos.

Os espaços privados retratados na obra grega e latina analisada pressupóem que deparemos lugares de incessante atividade: afora o justo repouso antigo, dos trabalhadores e as pausas devidas ao ritmo de vida usual do hom religiosas $^{37}$ ou de tempos em tempos entrecortado por festividades civicas, para o dia-a-dia de privadas, não há que se esperar o ócio absoluto como regra para o dia-a-dia de chefes ou comandados. Quanto à obra de Xenofonte, em que o kúpıs, sem imiscuir-se muito na parte material da labuta, conciliará a atenção ao papel de

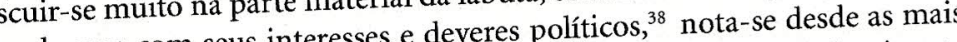
comento dominante altas "posições" a presença da industrio, e ainda, a seus dois tipos de subordinadas condutas: não cabe a ele, de início, e ainda, a .mãos à obra" quodos principais (a esposa e os escravos-chefe rurais), porem "máos a obra" quotidianamente e desde o alvorecer para garantirem a ordem e o sucesso do or $\chi 05$ na cidade ou no campo?

É importante ter em mente que essa entrega dos participantes ao esforço, ainda no contexto do Econômico, significa, além do zelo pela plena eficácia dos

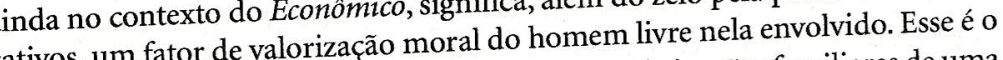
cativos, um fator de valorizaçáo macón familiares de uma caso de Iscoma não os diminui (por não tratar-se da mera busca do lucro), mas maneira que não os diminui (por ná fortalecê-los no corpo e no espírito. ${ }^{39}$ nobilita justamente por melhorá-los e fortalecê-los no corpo e no espícolas

No De agri cultura, por sua vez, a marcha contínua dos trabalhos agricolas, dita implacavelmente o próprio ritmo incessante da obr aqui, diante de um texto indentificável com a tentativa instruci fundus, antes de mais nada, um empreendimento lucrativo; ${ }^{41}$ por esse motivo, como explorar ao máximo a capacidade de trabalho em fazê-lo funcionar, sem grandes espaços para de todos os homens ocupados em

o que não seja efetivamente útil.

Como explicamos acima, tratando-se os tipos de propriedade diais $^{42}$ a crua Catão nesse livro de um vinhedo ou um olival com fobretudo para oferecer ao púpreceituação do autor direciona-se sem pausas sobretudo para oferecer ão público interessado no assunto (os próprios donos das terras e - por que nao? - os uilici suficientemente instruídos para lê-lo) um abrangente e minucioso panorama das várias etapas de produção do azeite ou do vinho. Ora, correspondendo (bem com essas atividades (bem objetos rúcos utilizáveis no dia-a-dia da plo da pecuária, da manufatura dos objetos rústicośn para abrigar homens, faina agrícola, da construção dos edifícios necessarios para abros sucessivas etapas animais ou colheitas, da cerealicultura, da floriculture dos esforços comuns a que todos devem consagrar-se com afinco, vemos descortinar-se diante de nós uma complexa cadeia de ações contínuas pensadas para resultarem, no final das contas, em vantagens para o senhor.

Embora afiancemos, por tal razão, que o fundus rusticus catoniano corresponde ao cenário onde se espera assegurar a prosperidade material de um dominus quase sempre ausente, isso não contribui para desprestigiá-lo do ponto de vista moral. Identificando-se a posse e a exploração da terra com o meio mais tradicional e respeitado de ganho entre gregos ${ }^{43}$ e latinos, ${ }^{44}$ os benefícios daí advindos jamais se confundiriam com um lucro vergonhoso para os favorecidos: pelo contrário, o sucesso nas colheitas ou na criação animal seria antes um indício do valor dos senhores, já que, mesmo quando não fisicamente envolvidos com o plantio ou o pastoreio, imaginar-se-iam os bons resultados no mínimo como produtos de sua seriedade no trato com o patrimônio e os escravos.

No entanto, é ao uilicus ideal, tal como descrito por Catão no capítulo $\mathrm{V}$ do De agri cultura, que compete "revestir-se" das atribuições do bom líder na maior parte das vezes. Conforme o dito, na impossibilidade da vigilância e atuação do dominus romano com o mesmo grau de envolvimento do kúpıs em Xenofonte, ${ }^{45}$ ele passa não só a representar o "braço" efetivo do senhor na dura concretude da vida rural, mas, em certo sentido, a "encarnar" com sua consorte algumas das "virtudes" do dono das terras, entre as quais se conta, a propósito da norma de funcionamento do fundus presentemente tratada, a dedicação exclusiva e laboriosa ${ }^{46}$ ao âmbito que o circunscreve.

Evidentemente, não há que se esperar para o bom uilicus a nobilitação moral proveniente da diligência nos trabalhos agrícolas que compete aos homens livres no contexto social greco-latino: como sabemos, trata-se de sociedades cuja desigual atribuição de valor aos indivíduos segundo suas raízes é algo, a princípio, intransponível; ${ }^{47}$ assim, um senhor digno ou indigno desse nome seria julgado apenas em confronto com homens de sua condição. Mutatis mutandis, o bom uilicus, se, por um lado, contrapõe-se ao mau pelo desempenho eficaz de suas obrigações rotineiras, por outro, enquanto simples instrumento a serviço das determinações do dono, nada mais teria feito do que adequar-se à meta esperada por condescendência ou receio dos castigos.

Se podemos concordar com que a hierarquia e a industriosidade são, de fato, pontos de relevância para o sucesso dos "empreendimentos" familiares tratados por um e outro autor, é preciso ainda conceder seu peso à racionalização dos fazeres e à orientação conjunta das práticas num único sentido. No primeiro caso, referimo-nos ao conjunto dos procedimentos "gerenciais" mostrados pelos autores como meios de aumentar o rendimento dos esforços comuns: afinal, de que adiantaria labutar muito mas em vão por falta de critério no desempenho de atividades a mostrarem-se, talvez, incoerentes com o plano 
se fundamenta na união das forças comuns pela meta de obtenção da prosperi dade, compreendida de forma abrangente. Isso justifica que seja necessário tomar muitas providências para coibir-lhes a fragmentação (ou favorecer-lhes a unidade), a exemplo do impedimento dos furtos internos, ${ }^{55}$ do castigo aos preguiçosos ou omissos, ${ }^{56}$ da própria seleção apenas daqueles adaptados a um certo perfil,$^{57}$ da busca de um entrosamento razoável entre todos os participantes $^{58}$ e das tentativas de tratamento igualitário ${ }^{59}$ para os cativos (a fim de evitar disputas pela concorrência excessiva).

\section{Conclusão}

Esperamos, nestas linhas, ter exposto aspectos de relevância para a compreensão dos "empreendimentos" tratados sob a imagem, apesar das eventuais divergências num e noutro meio cultural, de pequenos "nichos" sociais criteriosamente regidos por ditames destinados a garantir-lhes a funcionalidade ou, mesmo, a existência. Ainda, se não há que se esperar, nesses contextos específicos, a completa substituição dos costumes da sociedade compreendida em sentido mais amplo (haja vista a própria atribuição de poderes, em última instância, sempre ao homem livre), ${ }^{60}$ também não seria o caso de supor, ingenuamente, que os domínios familiares do homem grego e latino antigos procederiam apenas a uma "miniaturização" dos fenômenos observáveis nas interações sociais do mundo externo. Afinal, como propusemos desde o início, vemo-nos aqui diante de espaços a admitirem faces impensáveis no exterior, a exemplo mesmo da pronunciada descentralização das atribuições senhoriais: em quais outras esferas das sociedades antigas encontrar-se-iam, com tamanha naturalidade, mulheres ou escravos admitidos, nos termos descritos acima, a uma relativa "parceria" com os varões livres?

\section{Bibliografia}

BAILLY, A. Dictionnaire grec-français. Paris: Hachette, 1950.

BARBOSA, V. R. Resenha de Lessa, F. de S. O feminino em Atenas. Rio de Janeiro: Mauad, 2005. In. Clássica. Revista brasileira de estudos clássicos. São Paulo, v. 17/18, p. 333-335, 2004-2005.

BRIANT, P. et alii. Le monde grec aux temps classiques. Paris: Presses Universitaires de France, 1995. Tome I.

CATON. De l'agriculture. Texte ét., trad. et comm. par R. Goujard. Paris: Les Belles Lettres, 1975.

Organon, Porto Alegre, $\mathrm{n}^{0} 44 / 45$, janeiro-dezembro, 2008, p. 103-116 
DELLA CORTE, F. Catone Censore. La vita e la fortuna. Firenze: La Nuova Italia Scientifica, 1969

Tradução de V. M. Godinho. Lisboa:

GLOTZ, G. História

Cosmos, 1973.

HARVEY, P. Dicionário Oxford de literatura classica greg

Mário da Gama Cury. Rio de Janeiro: Zahar Ph.-E. Legrand. Paris: Les Belles HÉRODOTE. Hist

Lettres, 1946.

HORNBLOWER, S.; SPAWFORTH, A. The Oxford classical dictionary. Oxford:

University Press, 2003.

RIETO, M.-H. U. Dicionário de literatura grega. Lisboa: Verbo, s.d.

Pes Belles Lettres, 1985.

Latilina. Jugurtha. Fragments des "Histoires". Texte ét. et trad. par A. Ernout. Paris: Les Belles Lettres, 1974.

A. Ernout. Paris. Les Bella romana. I. Fase ascensionale. Napoli: Liguori, 1995.

. Werdt,

STEVENS, J. A. Friendship and profit in Xenophon's Oeconomicus.

P. A.V. (ed.). The Socratic movement. Ithaca/ London: Cornell University Press, 1994.

SUÉTONE. Vies des douze Césars. Texte ét. et trad. par H. Ailloud. Paris: Les Belles Lettres, 1961. Tome I.

Pranslated with a commentary by Sarah B.

Pomeroy. Oxford: Clarendon Press, 2001.

\section{Notas}

fomos obrigados a suprimir as Nota do editor: pedimos desculpas ao autor deste artigo proque fomos obrigados a sup conte de que citações em lín

dispunhamos. ${ }^{1}$ R. Goujard, no prefácio à edição Les Belles Lettres do De agri cultura Letones, 1975, p. XXIVl'agriculture. Texte ét., trad. et comm. par R. Goujard. Paris: Ler Catão; sem esgotá-lo no espaço XXXII), realizou o inventário completo das obras produzi a pri cultura, os discursos públicos, o desta nota, lembraríamos, a título de ilustração, alèm do De as Origines. O catálogo das obras de De re militari, os Praecepta ad filium, o Carmen de moribus e as Orizines. Ocloogia, os Memoráveis, De re milte or sua vez, inclui, além da Anabase, a Ciropédia, o Simposio, a Apologia, os Memoravsical Xenofonte, Ecor suamico, a Constituiçăo de Esparta (Cf. Hornblower, S.; Spawforth, A. The Oxford classical o Economico, a Constituiço de Ess 2003, p. 1629-1631).

dictionary. Oxford: University Press, 2003 p. 1629-1631). 39 anos com a chegada ao posto de ${ }^{2}$ Catão, assim, antes de atingir o topo do cursus honorum aos 39 anos no país sabino, soldado, "adcônsul da republica romana, passou pelas experiências de agricultore Censore. La vita e la fortuna. vogado", tribuno militar, questor e censor (cf. Della Corte, Ca aneniense rico e amigo de Sócrates,

Firenze: La Nuova Italia Scientifica, 1969). Quanto a Xenofonte, ateniense rico e amigo de Són coube-lhe liderar a expedição de retorno dos legionários gregos que partiram contra Ataxerxes, passar-se para o lado espartano contra o rei Farnábasos, ser exilado em 394 a.C. por seus compatriotas, descontentes com tal alinhamento e, enfim, terminar calmamente seus dias em Corinto (cf. Prieto, M.-H. U. Dicionário de literatura grega. Lisboa: Verbo, s.d., p. 435-443).

${ }^{3} \mathrm{Cf}$. resenha de Virgínia R. Barbosa a respeito da obra $O$ feminino em Atenas (Lessa, $\mathrm{F}$ de $S$. Rio de Janeiro: Mauad, 2005), in Clássica. Revista brasileira de estudos clássicos. São Paulo, v. 17/ 18, p. 333 2004/2005: "trabalhando com literatura, por todo exercício de minha profissão, e recorrendo aos documentos escritos, percebia neles, com desconforto, uma confirmação de que a mulher, realmente, não teve voz nem vez no mundo antigo". O mesmo, acrescentamos, poder-se-ia dizer da maior parte dos excluídos dos círculos privilegiados na Antigüidade (escravos, metecos, forasteiros e libertos em Roma).

${ }^{4} \mathrm{Cf}$. preâmbulo inicial de Hérodote. Histoires. Texte ét. et trad. par Ph.-E. Legrand. Paris: Les Belles Lettres, 1946: "esta é a exposição da História de Heródoto de Túrio, para que nem os feitos dos homens sejam apagados pelo tempo, nem as obras grandes e extraordinárias, realizadas por gregos e bárbaros, ressintam-se de glória".

${ }^{5}$ Cf. Salluste. Catilina. Jugurtha. Fragments des "Histoires". Texte ét. et trad. par A. Ernout. Paris: Les Belles Lettres, 1974, IV: statui res gestas populi Romani carptim, ut quaeque memoria digna uidebatur, perscribere. - "decidi os feitos do povo romano, apenas cada qual parecesse digno de lembrança, escrever por partes".

${ }^{6}$ Esse é, a propósito, o caso do De re publica ciceroniano e d'A república de Platão, tendo respectivamente, como alguns de seus interlocutores, Cipião Emiliano/ Lélio e Sócrates/ Polemarco.

${ }^{7}$ A própria idéia expressa pela palavra grega ờ $\chi 0 \zeta$, por sinal, admite um campo semântico bem mais amplo do que a noção material de "casa" em português. Assim, A. Bailly, em seu conhecido dicionário grego/ francês (Bailly, A. Dictionnaire grec-français. Paris: Hachette, 1950), oferece como traduções possíveis para esse termo grego, além de maison, salle à manger e temple, train de maison, biens, propriété e famille, race.

${ }^{8} \mathrm{~A}$ plena participação na vida política correspondia, para os atenienses e latinos dos séculos clássicos, a um privilégio dos cidadāos adultos nascidos homens e livres (cf. Briant, P. et alii. Le monde grec aux temps classiques. Paris: Presses Universitaires de France, 1995. Tome I, p. 134: la cité grecque est fondée sur de multiples exclusions: les étrangers, les métèques, les périèques, les esclaves (quelle que soit la forme de la dépendance), les jeunes et les femmes, mais aussi les affranchis, les bâtards, ceux qui exercent certains métiers reputés dégradants, autant d'individus exclus de cette "politeia" - "communauté des citoyens"). Para o caso romano, lembremos simplesmente uma iniciativa "depuradora" como aquela dotada por Augusto para regrar a inclusão no senado [apud Suétone Vies des douze Césars. Texte affluentem numerum deformi et incondita turba (erant enim super mille, et quidam indignissimi et post necem Caesarisper gratiam et praemium adlecti, quos orcinos uulgus uocabat) ad modum pristinum et splendorem redegit (...). - " "fez tornar o grupo crescente de senadores, uma turba disforme e confusa (pois eram mais de mil, alguns indigníssimos e aceitos depois da morte de César por favor ou recompensa, a quem o povo chamava orcini), ao antigo número e honradez (...)".] e, além disso, o caráter censitário e discriminatório da participação na vida pública, vetada, inclusive, aos libertos (cf. Harvey, P. Dicionário Oxford de literatura clássica grega e latina. Tradução de Mário da Gama Cury Rio de Janeiro: Zahar, 1987, p. 208: "pela emancipacáo formal o liberto romano, ao con cín con

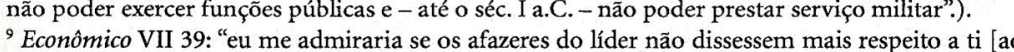
'Econômico VII 39: "eu me admirar

${ }^{10}$ De agri cultura V: rationem cum domino crebro putet. - "que freqüentemente preste contas [o uilicus] ao senhor".

${ }^{11}$ Cf. Sirago, V. Storia agraria romana. I. Fase ascensionale. Napoli: Liguori, 1995, p. 16: per Catone

Organon, Porto Alegre, $n^{2} 44 / 45$, janeiro-dezembro, 2008, p. 103-116 
ormai la tenuta agricola è un'azienda di produzione, con profitti e perdite: il buon proprietário è colu ormai la tenuta agricola e un'azenda diproduziones con profti è il fallimento.

che aumenta i profitti e diminuisce le perdite; in caso contranio enfallo Tre propla propriedade fundiaria conservava grande parte da tantos séculos; precisamente pelo facto de os estrangeiros de agricultor, pratica a exploraçāo directa. É prestígio (p. 217)./ O grande proprietario, como o pequeno ag modelo Iscómaco (p. 221).

ele que Xenofonte, no manual do "Económico", propóe como modelo Iscómaco (p. 221). ele que Xente diterrâneo ocidental pelos romanos, ${ }^{13} \mathrm{Ou}$ seja, na época do ganho completo da hege C.).

através da derrota definitiva de Cartago (146 a.C.). ${ }^{14}$ Cf. prefácio de Goujard na edição do De agri cultura citada (p.duzione specializzata, col principale 246: la campagna perde lo scopo dell

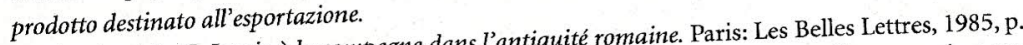
${ }^{5} \mathrm{Cf}$. Robert, J.-N. La vie à la campagne dans l'antiquite romaine. Pae venus à la ville pour y vivre un 27: et toujours paradoxalement, ces hommes [como Cicero], bien que venutant de fois que l'éloignemen existence souvent jugée plus facile, sont retournés aun

et leurs moyens financiers le leur permettaient.

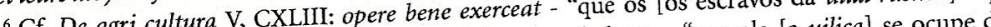

${ }^{6} \mathrm{Cf}$. De agri cultura V, CXLita trabalhar bem", cibum tibi et familiae curet uli cocum

cozinhar o alimento para ti [o uilicus] e os de casa". ${ }^{17} \mathrm{Cf}$. De agri cultura LVI: compeditis,

para os trabalhadores encadeiados". ${ }^{18}$ Cf. De agri cultura V: si quis quid deliquerit, pro noxa bo

uma falta, que bem o castigue de acordo com sua culpa". ${ }^{19} \mathrm{Cf}$. De agri cultura V: haruspicem, augurem, hariolum, chaldaeum, nequem cong"

năo deseje consultar um harúspice, um áugure,

${ }^{20} \mathrm{Cf}$. De agri cultura CXLIII (todo o capítulo). ${ }^{21} \mathrm{Cf}$. Stevens, J. A. Friendship and profit in Xenophon's Oeconomicus. In: Waerd, Lysias mentions Socratic movement. Ithaca/ London: Cornell University Press, 1994, p. 219 second, Lych and he says

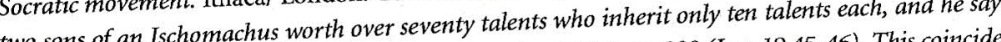
two sons of an Ischomachus wore the time of the speech, which is ca. 388 (Lys. 19.45-46). This coincides that this story dates well before the time of the speech, which is ca. with the portrait of Is

${ }^{22}$ Cf. supra nota 12.

${ }^{23}$ Cf. Econômico VII 10-43.

${ }^{24}$ Cf. Econômico VII 32: "e, disse ela, desempenhando quais a

parecem com as atividades que me é preciso desempenhar?" ?? ${ }_{25}$ Cf Econômico X 7: "então considera, mulher - Iscômaco contou ter dito -, que nom alvaiade nem da do carmim gosto mais do que da tua, mas, assim comelhas, os homens acham cavalos muito gratos aos cavalos, os bois

agradabilíssimo o mero corpo humano.

${ }^{26}$ Cf Econômico XI 15: "se nada for preciso na cidade, meu cscravo conduzo cavlo para o capo

Cr. Ecomoro o campo, talvez com mais proveito, ó Sócrates, do que se

caminhasse no xisto".

${ }^{27}$ Pois, de acordo com a divisão de tarefas explicada por Iscômaco à esposa (cf. Ec. VII 30), repatindo-se as atividades no âmbito privado entre duas funçôes essenciais (ob cor e conserviamente indo-se as atividades no âmbito priva delas (ganhar para trazer para a casa), compete obviamente do) e, cabendo ao marido un

mulher a segunda parc

${ }^{28} \mathrm{Cf}$. nota anterior
${ }^{29}$ Cf. Econômico VII 28: "nas que um é ineficiente o outro sendo capaz".

${ }^{30} \mathrm{Cf}$. Econômico VII 32-37.

${ }^{31} \mathrm{Cf}$. Econômico VII 32-34.

${ }^{32} \mathrm{Cf}$. Econômico IX 11: "fizemo-nos a governanta com a mente na que julgávamos mais comedid pelo estômago, pelo vinho, pelo sono e pelo contato com os homens, e, além disso, na que pareci especialmente ter a lembrança e a preocupação de nenhum mal sofrer de nossa parte por negligência e julgar, sendo-nos propícia, receber de nós a recompensa".

${ }^{33} \mathrm{Cf}$. Econômico XII 2: "com efeito, tenho intendentes nos campos"?

${ }^{34}$ Cf. Econômico XII 13-14.

${ }^{35}$ Cf. Econômico XIII 4-12.

${ }^{36} \mathrm{Cf}$. Econômico IX 6: "depois disso, separamos os adornos femininos para os festivais e as veste masculinas para os festivais e a guerra".

${ }^{37} \mathrm{Cf}$. De agri cultura V: feriae seruentur. - "que se observem os dias comemorativos",

${ }^{38} \mathrm{Cf}$. Econômico VII 3.

${ }^{39}$ Cf. Econômico VI 4-10.

${ }^{40} \mathrm{Cf}$. De agri cultura XXXIX: ne cessetur. - "que não haja pausas".

${ }^{41}$ Cf. supra nota 11.

${ }^{42}$ Cf. supra p. 4.

${ }^{43}$ Cf. Econômico VI 8: "concordamos com que, para um homem de bem, a agricultura é a melho ocupação e saber, e que dela os homens obtêm o que os favorece".

${ }^{44}$ Cf. prefácio do De agri cultura: at ex agricolis et uiri fortissimi et milites strenuissimi gignuntur, maxime pius quaestus stabilissimusque consequitur minimeque inuidiosus, minimeque male cogitantes sunt qui in eo studio occupati sunt. - "mas, dentre os que se dedicam à agricultura, saem homens do sunt qui in eo studio occupati sunt. - "mas, dentre os que se dedicam à agricultura, saem homens do
maior vigor e soldados da maior coragem; daí se obtém o ganho mais justo, seguro e o menos invejado, e minimamente insidiosos são os que se ocupam deste labor".

${ }^{45}$ Cf. supra p. 5 .

${ }^{46} \mathrm{Cf}$. De agri cultura V: uilicus ne sit ambulator, sobrius siet semper, ad cenam nequo eat. - "que o administrador não seja passeador, esteja sempre sóbrio e não vá banquetear-se em parte alguma”. ${ }^{47}$ Em Grécia e Roma, como vimos, sequer a libertação asseguraria ao ex-escravo direitos de fato idênticos aos do cidadão já nascido livre (cf. supra nota 8).

${ }^{48} \mathrm{Cf}$. De agri cultura XXVI.

${ }^{49}$ Cf. Econômico VIII 1: "de modo algum, ó mulher, venhas a desconcertar-te por não poderes dar o que me calha pedir a ti".

${ }^{50} \mathrm{Cf}$. De agri cultura LXXIII: pellem anguinam ubi uideris, tollito et condito, ne quaeras cum opus siet. - "quando vires uma pele de serpente, recolhe-a e conserva-a para não precisares procurar por uma quando houver necessidade".

${ }^{51}$ Cf. Econômico IX 3: "pois o quarto, estando na parte mais protegida, pedia os enxovais e a mobília mais preciosos".

${ }^{52} \mathrm{Cf}$. De agri cultura V: opera omnia mature conficias face, nam res rustica sic est: si unam rem sero feceris, omnia opera sero facies. - "procura terminar todo o trabalho cedo, pois assim são os trabalhos do campo: se fizeres uma parte deles com atraso, farás todo o trabalho com atraso".

${ }^{53}$ Pois a natureza e a agricultura, menos abordadas pelo viés técnico neste texto, surgem nele sob a marca de uma forte generosidade. Isso explica que as "recomendações" de Iscômaco a Sócrates celo mundo, assumindo antes o sentido de um despertar para as razoáveis exigências da agricultura do que de algo a impor-

Organon, Porto Alegre, ㄲo 44/45, janeiro-dezembro, 2008, p. 103-116 
se pela vontade e interesse humanos.

${ }^{54}$ Cf. supra nota 26.

${ }^{55} \mathrm{Cf}$. De re rustica XIII: lectum stratum ubi duo custodes liberi cubent. - "um leito arrumado onde se deitem dois vigias livres".

${ }^{56}$ Cf. supra nota 32.

${ }^{57}$ Cf. supra nota 32 e p. 8.

${ }^{58} \mathrm{Cf}$. Econômico VII 37: "por Zeus, disse a mulher, agradabilíssimo, se os [escravos] bem tratados vão mostrar-se agradecidos e ser mais benevolentes do que antes".?

${ }^{59} \mathrm{Cf}$. supra nota 17.

${ }^{60}$ Cf. supra p. 3. 